\title{
Crucial Importance of Work Productivity in the Conditions of a-Typical Employment
}

\author{
Małgorzata Dobrowolska \\ Silesian University, Institute of Psychology, Faculty of Work and Organisational Psychology \\ malgorzata.dobrowoska@us.edu.pl
}

\begin{abstract}
:
Work productivity is of crucial importance to all employers regardless of what solutions they use, traditional or flexible ones. Most human resource management programs are oriented on HR tools that are favourable for employee efficiency, and hence on organizational effectiveness and productivity. When examining different psychological variables that are relevant in psychology of work and organization, popularity and productivity prove to be vital, since this variable correlates with all the remaining psychological dimensions due to continuous and intensive search for ways to improve efficiency in the work place. This article presents the results of the research carried out on $n=2118$ a-typical employees.
\end{abstract}

Keywords: work productivity, a-typical employment, praxeology

\section{Introduction}

Each time in case of assessment of performance, regardless of measurement applied, efficiency, effectiveness, performance, productivity, or other praxeological differentiators, the intention of management specialists is the same improvement of work performance.

Analysis of productivity may concern individual effects of work - an individual employee, a team of employees, that is employee group, an organizational unit - a section, a department, an organisation as a whole. Work assessment systems allow for measurement of the above factors taking into account flexible forms of employment (compare: Dobrowolska, 2014), organisational effects are the outcome of actions of specific units, as well as non-organizational factors such as a modification of legal regulations, crisis, cataclysm. Work effects may be quantitative and qualitative, social, organizational and may even be analysed from the perspective of an entire company. Undoubtedly organisations that use traditional and non-traditional employment models face the same problems related to work productivity.

\section{Presentation of the author's research}

The respondents were $n=2118$ people working in 9 flexible forms of employment: substitute work in accordance with Article 25 Point 1 of the Labour Code; temporary employment as understood by the Act on employment of temporary employees as from 9 July 2003 (Journal of Law 03. 166. 1608); self-employed, self-employment as understood by the Act 2 July 2004 on freedom of economic activity; teleworking in accordance with Article 675 and following of the Labour Code; employment for a specified period of time in accordance with Article 25 Point 1 of the Labour Code; employment in part-time work in accordance with Article 292 Point 1 of the Labour Code; work under a civilian-legal agreement on the basis of the freedom to contract i. e. Article 3531 Point 1 of the Civil Code; seasonal work in accordance with Article 25 Point 1 of the Labour Code; employment in the social economy, which includes: social co-operatives, cooperatives, cooperatives of the disabled and the blind, non-governmental organizations and entities listed in Article 3 Section of the Act from 24 April 2003 on public benefit and voluntary services (Journal of Law dated 29 May 2003 as amended).

Among 2118 respondents, $44 \%$ are women and $56 \%$ are men. Due to the number 0 the respondents it can be concluded that the analyses sample suggests lack of a visible disproportion between men and women with respect to flexible forms of employment.

Flexible employees have been divided into 9 professional groups, each of them with more than 200 people. The featured groups were as follows: $12.1 \%$ working for a specified period of time; $13.2 \%$ working part-time; $10.7 \%$ working on 
contract; $10.3 \%$ of the self-employed; $10.4 \%$ of teleworkers; $10.4 \%$ working under a substitute work contract; $12.4 \%$ of temporary workers; $10.0 \%$ of seasonal workers; $10.5 \%$ of the employed in the social economy.

The respondents were adults of different ages, although all the respondents were in the so-called age a professional activeness, working age from 18 to 60 years for women and up to 65 years for men. $7 \%$ of the respondents were 18- 24 years old. The largest group - $42 \%$ are persons aged $25-34$. 34\% of the respondents are 35 to 44 years old. Another $12 \%$ of the respondents are between $35-44$ years, while $5 \%$ of the respondents were 55-65 years. An average age in the analysed group was 36 , and the median was 35 years. The youngest respondent was 18 years old, and the oldest 65 years old. The distribution of results in the Polish sample of the tested fits fully into the European characteristics of flexible employees, which describes them as rather young, with an average period of employment in an organization - less than five years (Nollen, 1996).

Flexible employees who took part in the research are well-educated. More than half of the respondents $(56 \%)$ holds a university degree. Quite a large group of the respondents - $34 \%$ are people with secondary education. $6 \%$ of the respondents has a vocational education and only $4 \%$ of the respondents have primary education. Persons without any education represent only $0.3 \%$ of the sample. This is an interesting result in view of the fact that a social perception of flexible employment is related to a stereotypical and pejorative image of this type of employment regarded as " junk one" for poorly skilled ones. As it turns out, however, in majority of cases people involved in these forms of employment are welleducated.

Seniority of flexible employees fluctuates between a few months and several decades (maximum 41 years), the average was 8,5 years. Seniority of the biggest number of the respondents is up to 5 years $-42.6 \%$, the smallest number of the respondents is of a considerable seniority, which also corresponds to the already mentioned European characteristics of an average flexible employee (Nollen, 1996). Seniority was divided into 6 categories. The first group, up to 5 years, includes 42. $6 \%$ of the respondents and the second one from 6 to 10 years $-29.8 \%$, the third from 11 to 15 years $-11.0 \%$, in the group of seniority from 16 to 20 years $-8.9 \%$ of respondents, from 21 to 30 years $-5.6 \%$ of the respondents and in the last group above 31 years - only $2.1 \%$.

In the majority of cases the researched flexible employees has had 2 - 3 employers so far (47 \%). 14. $6 \%$ of them have worked in only 1 place of work. The remaining respondents have changed work more often. $28 \%$ of them worked for 4 - 5 employers, and $12 \%$ of them had more than 5 employers. The results show a relatively small migration between employers, which might be expected in flexible employment.

Flexible employees who took part in the survey have worked under their current work contract for 5.5 years on average. A detailed distribution of responses with respect to the time categories is show on the chart below. Paradoxically, the highest percentage are people working not only under short-term contracts, up to one year - $19.3 \%$ and up to two years - $19.0 \%$, but also people with long-term employment relationship, more than 10 years. In the group from 2 to 3 years there is $12.4 \%$ of the respondents, in the group from 3 to 4 years - $8.2 \%$ of the respondents, from 4 to 6 years $15.0 \%$ of the respondents, from 6 to 10 years $10.6 \%$ of the respondents.

When it comes to location in the structure, the largest part of the respondents are subordinates $(62 \%)$. Flexible employees are also specialists $(29 \%)$, but less often managers $(7 \%)$ or directors $(2 \%)$.

More than half of the surveyed flexible employees $(54 \%)$ works in the private sector. $34 \%$ of the respondents is employed in the public sector, and the remaining part is employed the social sector $(12 \%)$. The private sector uses flexible employment solutions much more often than the public one.

The biggest number of the respondents is employed in the public administration $(31.8 \%)$ and in the services sector (28. 5 $\%)$. The smallest number of the respondents works in health care $(2.3 \%)$ and education $(9.3 \%), 11.3 \%$ of the respondents is employed in trade.

The variable work productivity is regarded as a subject-and- organizational determinant of behaviour of employees in nontraditional employment. It was decided that the variable efficiency should be kept and intuitive measurements should be applied while adding two questions measured separately by a total sum of results in a given question. The first question is as follows:"I think that I have been working effectively", the second - "I believe that I am a good employee", which the respondents answer using a scale from 1 (I do not agree) to 5 (I agree completely). The respondents working under flexible 
contracts are generally regarded as effective employees. $88 \%$ of the respondents agree with the statement "I believe that I have been working effectively", including $50 \%$ of the respondents who agree with it completely. $89 \%$ of the responders consider themselves to be good employees, including $54 \%$ who agree with is completely.

While analysing the responses to the above questions, taking into account their forms of employment, one can see a statistically significant correlation between these variables. Analysis of a correlation using Kramer's V showed a statistically significant correlation between a form of employment and answers to the question "I believe I am an effective employee". Value of the factor is 0.108 and indicates weak correlation. The highest percentage of respondents who consider themselves to be effective employees was observed in the following groups: the self-employed, individuals working parttime, teleworkers and individuals working for a specified period of time. Whereas the lowest percentage of people who think they are effective employees was to be found in the following groups:individuals working under a substitution contract, individuals working under commission contract and temporary workers. Analysed results may be due to the specific nature of employment conditions. For self-employment promotes efficiency, which is directly linked with the work results, which translates into financial gratification. Relatively longer contracts in part-time work, individuals working for a limited period of time or teleworkers and privileges of the Labour Code may translate into a level of work productivity. Whereas characteristic for short contracts works without social securities carried out under commission contracts, temporary jobs and substitute works are not beneficial for work productivity of employees.

Distribution of responses to the statement "I believe that I am a good employee" are similar the one obtained for the first question. Also here the highest interest of individuals agreeing with this statement occurred in the following groups:individuals working under a contract for a specified period of time, individuals working part-time and the selfemployed. While the smallest number of individuals who share this point of view was found in the following groups:individuals working under commission contracts and substitution contracts.

Work productivity significantly correlates with sex, education, occupation, industry and marital status. No correlation was obtained with the variables of age, sector, seniority, number of employers, duration of contracts, place of residence and number of children.

Correlation analysis has shown that there is a relationship between a sense of productivity and sex. Kramer's $\mathrm{V}$ is 0.098 ; $p<0.01$. Percentage of the respondents who consider themselves effective was higher among men $(57 \%)$ than among women $(50 \%)$. Education affects the sense of effectiveness, too; Kramer's $V=0.158 ; p<0,001$. In the group of the respondents with education below secondary school the percentage of individuals claiming to be effective employees is 48. $8 \%$. This is the lowest value in comparison to the remaining groups: among employees with primary education the percentage was $51.2 \%$, and among people holding a university degree it was $56 \%$. Also, age significantly differentiates responses concerning effectiveness (Kramer's $V=0.170 ; p<0.001$ ). The highest percentage of the respondents convinced of their productivity was observed in the group of professionals and free-lancers $(55.1 \%)$. In the groups of directors, CEOs and business owners as well as technicians and civil service officials, trade and services workers the results are similar $51-52 \%$ believes that they are productive. The lowest percentage of people who claim that they are effective was found in the group of workers $-47.9 \%$. Statistically significant differences also occurred in the responses after taking into account specific sectors (Kramer's $V=0.172 ; p<0.001$ ). The highest percentage of positive responses to the question concerning productivity was found among heavy industry employees (63.3\%) and other sectors $(60.7 \%)$. A group of persons working in the public administration and services are similar - $52 \%$ are considered to be effective. The lowest percentage of people who think they are the effective employees occurred in the group of trade employees - 48. $6 \%$. There were also statistically significant differences in the responses to the question on productivity in terms of the respondents' marital status, Kramer's $V=0.125, p<0.001$. The divorced or the widowed $(56.4 \%)$ consider themselves effective more often than the interviewed married males and females (53.7\%) and maidens and bachelors (49. $9 \%)$.

Summing up, productive employees are those holding a university degree, holding top positions - CEOs, directors, business owners, individuals representing industry, the divorced, the widowed and mainly women. Persons who consider themselves to be good employees are mainly women (correlation with sex), persons holding a university degrees (correlation with education), senior executives in the organization (correlation with the profession) and residing in big cities (correlation of the place of residence).

Analysis of correlations shown that there is a relationship between conviction of being a good employee and sex. Kramer's $V$ is $0.085 ; p<0.05$. Percentage of the respondents who consider themselves effective was higher among women (59. $2 \%)$ 
than among men (55. 2\%). Education affects significantly the responses of the respondents to the analysed question, Kramer's $V=0.155 ; p<0.001$. The higher education, the higher the rate of responders considering themselves good employees. In the group of the respondents with education below secondary school the percentage of individuals claiming to be good employees is $51.2 \%$. In the group of the respondents with secondary education the percentage is $53.8 \%$, and in group of people holding a university degree $=59.8 \%$. There was also a statistically important correlation between profession and a sense of being a good employee, Kramer's $V=0.173 ; p<0.001$. The lowest percentage of people claiming they are good employees was in the group of workers $(52.1 \%)$. In the remaining groups this percentage is as follows: directors, CEOs, business owners: $59.0 \%$; professionals and professional services (freelancers): $58.6 \%$; technicians and civil service officers: $57.4 \%$; employees working in trade and services: $55.1 \%$. The respondents' reaction to the analysed question differ with respect to their place of residence, Kramer's $V=0.116 ; p<0.05$. The biggest number of the respondents who consider themselves good employees was observed among big city dwellers $(60.3 \%)$. In small towns and villages this percentage is lower (56. $5 \%$ and $52.1 \%$ respectively).

\section{Conclusion}

Rapid development of flexible organizational solutions designed to primarily reduce labour costs involves changes in HR policy and imposes employment of employees in non-traditions employment forms. Employees are therefore subject to penalties, requirements and rules that are different from those described so far in literature of psychology of work. These descriptions, as it has already been mentioned, are based on analyses of staff employed in traditional forms of employment, colloquially referred to as the permanent ones, and therefore become useless in the new conditions. in this context doubts are risen by every aspect of broadly understood psychology of work (cf. Dobrowolska, 2012).

\section{References:}

[1] Dobrowolska M. (2012). Employee and flexible forms of employment - a theoretical analysis and empirical studies. Poland: Warsaw University Press

[2] Dobrowolska M. (2014). On the issues of employment flexibility. Research and conclusions. Poland: Difin Press.

[3] Nollen, S. D. (1996). Managing contingent workers: how to reap the benefits and reduce the risks. New York: American Management Association. 